\title{
Cardiovascular and Cerebrovascular Prognosis at 5 Years of Patients Who Presented with an Ischemic Stroke at Principal Hospital of Dakar
}

\author{
Waly Niang Mboup ${ }^{1 *}$, Mame Madjiguène Ka1 ${ }^{1}$, Serigne Cheikh Tidiane Ndao ${ }^{1}$, Demba Ware

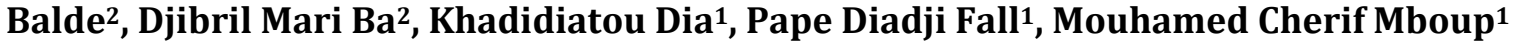 \\ ${ }^{1}$ Department of Cardiology Principal Hospital/Dakar (HPD), Dakar, Senegal \\ ${ }^{2}$ Department of Cardiology Military Hospital of Ouakam/Dakar (HMO), Dakar, Senegal \\ Email: *wnmboup.91@gmail.com
}

How to cite this paper: Mboup, W.N., Ka, M.M., Ndao, S.C.T., Balde, D.W., Ba, D.M., Dia, K., Fall, P.D. and Mboup, M.C. (2022) Cardiovascular and Cerebrovascular Prognosis at 5 Years of Patients Who Presented with an Ischemic Stroke at Principal Hospital of Dakar. World Journal of Cardiovascular Diseases, 12, 77-86.

https://doi.org/10.4236/wjcd.2022.121008

Received: September 13, 2021

Accepted: January 27, 2022

Published: January 30, 2022

Copyright $\odot 2022$ by author(s) and Scientific Research Publishing Inc. This work is licensed under the Creative Commons Attribution International License (CC BY 4.0).

http://creativecommons.org/licenses/by/4.0/

\begin{abstract}
Aims: To determine the cardiovascular and cerebrovascular prognosis at 5 years of patients who underwent an ischemic stroke in Senegal. Methods: We performed a descriptive, retrospective and exhaustive study conducted at Principal Hospital of Dakar. We included all patients hospitalized at Principal Hospital of Dakar from 2013 to 2019 for an ischemic stroke confirmed by a cerebral CT-Scanner or by magnetic resonance imaging, and who survived the acute phase. Results: Overall, one hundred and seventy-one (171) patients were gathered. Ninety-six (96) male patients account for $56.14 \%$ and seventy-five (75) female patients account for $43.86 \%$, with a sex ratio of 1.28 . Patients' mean age was $66.33 \pm 13.99$ years. Twenty-one (21) young patients (12.35\%), aged less than 50 years, presented with an ischemic stroke. Myocardial infarction was found in a female patient $(0.6 \%) 3$ months after she experienced an ischemic stroke, nine (9) patients (5.29\%) underwent a recurrence of the ischemic stroke with a mean recurrence period of 8 months and extremes ranging from 1 to 24 months. Five (5) patients (2.92\%) developed dementia with a score less than 28. A 30 years old patient presented with epilepsy 12 months after the ischemic stroke accounting for $0.58 \%$. We registered ninety (90) deaths that occurred in a mean period of 24 months \pm 9.8 after they presented their ischemic stroke, standing for $52.63 \%$ amongst which thirty-five (35) accounting for $39 \%$ were female patients and fifty-five patients (55) representing 61\% were male patients. Mortality-related factors included: advanced age, past medical history of heart surgery, known as dyslipidemia, physical inactivity, obesity and recurrent ischemic stroke. Conclu-
\end{abstract}


sion: Long-term prognosis of ischemic stroke remains unclear in Senegal. Therefore, a strategy for primary prevention is highly crucial and it requires the control of risk factors in general and that of high blood pressure in particular.

\section{Keywords}

Cardiovascular, Cerebrovascular, Prognosis, Ischemic Stroke, Dakar

\section{Introduction}

Ischemic Stroke (IS) includes Transient Ischemic Attack (TIA), subsequent stroke and cerebral venous thrombosis. They represent $80 \%$ of strokes. Over the last two decades, several scientific studies were devoted to this pathology, which is considered today as an emergency in the same way as myocardial infarction [1].

The prevalence of cerebral vascular events should increase in the upcoming years due to the aging of the world population and the rise of major risk factors such as hypertension, diabetes, smoking and obesity [2] [3].

Cerebralvascular Events (CVE) are well-known to be a major public health concern, the main cause of acquired disability in adults, the second cause of dementia after Alzheimer's disease and the third cause of mortality in western countries after hearts diseases and cancers [2] [4] [5].

Ischemic strokes prognosis is remarkable by a high risk of recurrence and death due to a cerebrovascular cause if the risk factors are not under control.

Studies performed in South Africa showed that black people tend to have more strokes than white people due to a high prevalence of cardiovascular risks in our population.

Also, black people tend to have more complications and the mortality rate is higher than in any other race. These differences in prevalence, gravity and mortality, of strokes are observed even in biracial studies [6] [7].

The aim of this work was to determine the cerebrovascular and cardiovascular prognosis at 5 years in patients who presented with an ischemic stroke in Senegal.

\section{Methodology}

This retrospective and descriptive study was conducted at the medical wards of Principal Hospital of Dakar. We included all patients admitted at Principal Hospital of Dakar from 2013 to 2019 for an ischemic stroke confirmed by a cerebral CT-Scanner or by magnetic resonance imaging, and who survived the acute phase.

We excluded patients who died during the hospitalization and those we lost follow-up.

We evaluated the cerebrovascular prognosis: 
- Recurrent ischemic or hemorrhagic stroke;

- The time limit before a recurrence and associated factors;

- The onset of dementia evaluated with the Senegal's score;

- The occurrence of vascular epilepsy;

- Persistence of the motor deficit.

We evaluated the cardiovascular prognosis: myocardial infarction, occlusive arteriopathy of the lower limbs, cardiac failure and death related to a cardiovascular cause. We also evaluated the mortality and associated factors.

The parameters studied were entered and processed through SPHINX, Excel and SPSS Software (Windows 2016 version). Quantitative variables were expressed as mean value more or less standard deviation and qualitative variables were expressed as percentage.

We compared the features of the living patients and the deceased one in order to determine the risk factors associated to the mortality. We used the Chi-square test to assess the qualitative values, and the ANOVA test to evaluate the quantitative values. A $\mathrm{p}$ value $<0.05$ was considered statistically significant.

\section{Results}

\section{Clinical features}

In total, one hundred and seventy-one 171 patients were gathered. Ninety-six (96) male patients account for $56.14 \%$ and seventy five (75) female patients account for $43.86 \%$, with a sex-ratio of 1.28 . Patients' mean age was $66.33 \pm 13.99$ years. Twenty-one (21) young patients (12.35\%), aged less than 50 years, underwent an ischemic stroke. The socio-demographic characteristics of the patients are shown in Table 1.

About past medical history, we found: a mitral stenos is in 6 patients, a myocardial infarction in 4 patients and an ischemic stroke in 26 patients. Four (4) patients were carrying valvular prosthesis.

Hypertension was the main cardiovascular risk factor with a proportion of $46.1 \%$ of female patients and $53.9 \%$ of male patients. Diabetes was found in 62 patients (36.26\%) amongst which 31 were male patients (50\%) and 31 were female patients (50\%). Tobacco addiction (smoking) was found in 2 female patients (6.89\%) and 27 male patients (93.10\%). All patients have observed smoking cessation for more than 3 years. Fifty nine (59) patients so $39.6 \%$ had dyslipidemia amongst which 23 were male patients $(38.98 \%)$ and 36 were female patients $(61.02 \%)$.

Table 1. Socio-demographic characteristics of the patients.

\begin{tabular}{ccc}
\hline Socio-demographic characteristics & Population & Percentage (\%) \\
\hline Male patients & 96 & $56.14 \%$ \\
Female patients & 75 & $43.86 \%$ \\
Patients aged less than 50 years & 21 & $12.35 \%$ \\
\hline
\end{tabular}


Table 2 highlights the risk factors found in the patients and their past medical history.

\section{Cerebrovascular prognosis}

The risk of recurrent ischemic stroke was the main cerebra-vascular complication found in 9 patients (5.29\%). The mean period between the first episode and the recurrence was 8 months with extremes of 1 and 24 months. The medium value of the Senegal's test was 34.42 with extremes of 17 and 39. Five (5) patients $(7.9 \%)$ developed dementia with a score of Senegal lower than 28 . Three of them were male patients and two (2) of them were female patients. One (1) female patient developed epilepsy 12 months after the ischemic stroke corresponding to $0.58 \%$. About motor deficiency, we noticed: one (1) case of motor aphasia, three (3) cases of central facial paralysis, one (1) case of left monoplegia, one (1) case of left hemiparesis, three cases (3) of non proportional left hemiplegia, one (1) case of right hemiplegia and one (1) case of total hemiplagia. Nevertheless, $48 \%$ of the patients fully recovered from their deficit. Distribution of patients according to cerebrovascular complications is shown in Table 3.

Table 2. Distribution of patients according to cardiovascular risks factors and past medical history.

\begin{tabular}{ccc}
\hline CV RF and PMH & Population & Percentage (\%) \\
\hline Hypertension & 128 & $74.85 \%$ \\
Diabetes & 62 & $36.26 \%$ \\
Dyslipidemia & 59 & $39.6 \%$ \\
Smoking & 29 & $16.96 \%$ \\
Obesity & 32 & $61.1 \%$ \\
Physical Inactivity & 44 & $31.65 \%$ \\
Valvular Prosthesis & 04 & $2.3 \%$ \\
Mitral Stenosis & 06 & $3.5 \%$ \\
At Least One Episode of Ischemic Stroke & 26 & $15.2 \%$ \\
Occlusive Arteriopathy Of The Lower Limbs & 01 & $0.58 \%$ \\
MI & 04 & $2.33 \%$ \\
Chronic Coronary Syndrome & 01 & $0.58 \%$ \\
\hline
\end{tabular}

MI: Myocardial infarction.

Table 3. Distribution of patients according to cerebrovascular complications.

\begin{tabular}{ccc}
\hline Cerebrovascular complications & Number of patients & Percentage \\
\hline Recurrent ischemic stroke & 9 & $5.29 \%$ \\
Dementia & 5 & $2.92 \%$ \\
Epilepsy & 1 & $0.58 \%$ \\
Residual motor deficit & 89 & $52 \%$ \\
\hline
\end{tabular}




\section{Cardio-vascular prognosis}

Regarding cardiovascular complications, we found one case of myocardial infarction in a female patient (0.6\%) 3 months after she experienced an ischemic stroke.

\section{Mortality}

We recorded ninety (90) deaths that occurred in a mean period of 24 months \pm 9.8 after the ischemic stroke corresponding to $52.63 \%$ amongst which 35 (39\%) were female patients and 55 were male patients $(61 \%)$, the mean age was 70 years old \pm 12.48 with extremes of 30 and 99 years old. Mortality-related factors were: advanced age, past medical history of heart surgery, a known dyslipidemia, physical inactivity, obesity and ischemic recurrent stroke as shown in Table 4.

\section{Discussion}

Our work included 171 patients with a mean age of $66.33 \pm 13.99$ years old.

Our mean age is similar to those of other African studies and confirms that ischemic stroke belongs to the pathologies of the elderly population with 60.8 (22 - 84) in a study reported by Bendriss et al. [8] [9] [10] [11] and 62.2 (35 - 95) in that of Coulibaly et al. [12].

The results of our study match with literature data that show that hypertension is the most represented modifiable risk factor in the occurrence of strokes [3] [13] [14] [15]. Dyslipidemia was the second modifiable main risk factor after hypertension representing 39.6\%. That prevalence matches with the Belgian study reported by Savsina et al. [16] which included 14,868 patients who underwent an ischemic stroke and in which hypercholesterolemia (46.5\%) was the second risk factor in terms of frequency after hypertension.

The prevalence of diabetes in patients with cerebral infarction ranged from 15 to $33 \%$ [17] [18] [19] [20]. Similarly to our study, we have 36.26 of associated cases with subsequent cerebral vascular event. Smoking is a risk factor of carotid atherosclerosis: a meta-analysis [21] shows that the relative risk of ischemic stroke is 1.9. We noticed smoking in $16.96 \%$ of our patients, on the other hand Kane et al. [22] highlighted that $3.12 \%$ of the patients were smokers.

\section{Cerebra vascular prognosis}

After an ischemic stroke and a transient ischemic attack without treatment,

Table 4. Mortality-related factors.

\begin{tabular}{cccc}
\hline & Deceased patients & Living patients & P value \\
\hline Mean age (years) (standard deviation) & 70 ans $( \pm 12.48)$ & 61 ans $( \pm 14.86)$ & 0.001 \\
Past medical history of heart surgery & $00(00 \%)$ & $04(6.30 \%)$ & 0.014 \\
Dyslipidemia & $29(32.2 \%)$ & $25(39.7 \%)$ & 0.034 \\
Physical inactivity & $24(26.7 \%)$ & $17(26.9 \%)$ & 0.022 \\
Obesity & $15(28.8 \%)$ & $08(8.7 \%)$ & 0.002 \\
Recurrent ischemic stroke & $06(9,5 \%)$ & $04(4,4 \%)$ & 0.05 \\
\hline
\end{tabular}


the risk of recurrence is about $10 \%$ at one week, $15 \%$ at one month [23], 25\% at five years and $40 \%$ at ten years [24].

In our study, $5.29 \%$ of the patients had a relapse in a mean period of 8 months with extremes range from one (1) month to two (2) years. This result is a bit similar to that of Hardie et al. [25]; they found that the risk of recurrence was higher in the first six months following the first episode of stroke. The mean annual risk was at $4 \%$ after one (1) year.

Although there is a large consensus about the fact that stroke is an increased risk of subsequent dementia, the results of previous studies about the prevalence of post stroke dementia are contentious: dementia rates 3 months after the stoke vary from 6\% [26] to more than 30\% [27] and the data regarding risk factors are inconsistent.

In our study, $2.92 \%$ of the patients developed dementia, which is inferior to that of an English meta-analysis reported by Sarah et al. [28] who showed a rate of $10 \%$. The incidence of epilepsy after a stroke in the elderly varies from $2 \%$ to $14 \%$ according to the study population, the type of stroke and the definition of epilepsy [29]-[36]. We obtained $0.58 \%$ of epilepsy occurring on young people after an ischemic stroke, unlike Arntz et al. [37] who obtained 14.4\% of epilepsy occurrence after an ischemic stroke. This difference in the results is methodologi$\mathrm{cal}$ in reference to the test used for the evaluation of dementia.

A standing period after a stroke, the evolution is variable. In our study, $48 \%$ fully recovered without after-effects whereas $52 \%$ had a partial recovery with various sequellae (aphasia, total hemiplegia, monoplegia, Our result is close to what Bendriss et al. [8] obtained with $24.5 \%$ of full recovery and $50 \%$ of partial recovery avec remaining sequellea. However, these results are different from those of Ducrocq et al. [38] with $46 \%$ of recovery without after-effects and $34.7 \%$ of partial recovery with sequellea. This difference can be explained by an early management and the young age of his study population.

\section{Cardio-vascular prognosis}

In our population, 1 case $(0.6 \%)$ of myocardial infarction was noticed during the evolution. It is close to the study reported by of Bendriss et al. [8] where $4,5 \%$ of the patients developed cardiovascular complications (myocardial infarction, peripheral artery disease). However, Kang et al. [39] found in their study (Corean) $13.7 \%$ of patients experienced major cardiovascular pathologies. The low rate of cardiovascular complications found in our study is probably underestimated due to the retrospective design of our work. Among those multiple deaths, some are probably related to cardiovascular complications.

\section{Mortality}

In our study, the mortality rate was high, estimated at $52.6 \%$ with a mean delay of two (2) years. Mudzi et al. [40] performed a study on 200 patients with a one-year follow-up after the ischemic stroke; a mortality rate of $25.5 \%$ at 3 month, $35.5 \%$ at 6 month and $38.0 \%$ at 12 month was found. Regardless of the differences on these rates, all these studies outline that outcome after an ischemic 
stroke is particularly unclear in the elderly population with numerous comorbidities.

Our work shows that age is a factor of bad prognosis with a risk of death that increases in parallel to age. In fact, the mean age is 61 years \pm 14.86 and 70 years $\pm 12.48(\mathrm{p}=0.001)$ respectively in living patients and deceased patients.

In our study, we have found that the factors linked to the mortality rate were: advanced age, past history of heart surgery, a known dyslipidemia, physical inactivity, obesity and recurrent ischemic stroke. We have a common factor to that of Coulibaly et al. [12] in 2019 who found past history of stroke and obesity to be factors linked to the mortality rate; to that of Bezzaoucha et al. [41] in 2020 who found that the risk of dying from a stroke increased considerably with age; Kielbergerová et al. [42] who found that advanced age, bad control of glycemia and atrial fibrilation were linked to the death in their population.

The limits of this study are due to its retrospective characteristic but also, to the lack of availability of the patients.

\section{Conclusion}

The long-term prognosis of patients with ischemic stroke is particularly unclear in Senegal. The evolution is labeled with a residual risk of recurrent ischemic stroke and with a particularly high mortality rate. Cardiovascular complications seem to be rare but they are probably underestimated and explain, partly, this heavy mortality rate. The unclear prognosis of these patients should call out practitioners and public authorities in Sub-Saharan Africa to initiate and make viable activities of awareness about all the risk factors that contribute to the occurrence and the recurrence of the vascular cerebral accident. Prospective studies should be realized to precise causes of death on the polyfactorial elderly.

\section{Conflicts of Interest}

The authors declare no conflicts of interest regarding the publication of this paper.

\section{References}

[1] Mazaux, J.M., Lion, J. and Barat, M. (1995) L'hémiplégie au stade initial. In: Rééducation des hémiplégies vasculaires de l'adulte, Masson EDT, Paris, 1-11.

[2] Redon, J., Olsen, M.H., Cooper, R.S., et al. (2011) Stroke Mortality and Trends from 1990 to 2006 in 39 Countries from Europe and Central Asia: Implications for Control of High Blood Pressure. European Heart Journal, 32, 1424-1431. https://doi.org/10.1093/eurheartj/ehr045

[3] Warlow, C., Sudlow, C., Dennis, M., Wardlaw, J. and Sandercock, P. (2003) Stroke. The Lancet, 362, 1211-1224. https://doi.org/10.1016/S0140-6736(03)14544-8

[4] Zuber, M. and Mas, J.L. (1992) Epidemiology of Cerebrovascular Accidents. Revue Neurologique, 148, 243-255.

[5] Lavallée, P.C., Labreuche, J., Spieler, J.F., Jougla, É. and Amarenco, P. (2007) Stroke and Vascular Mortality Trends in France: 1979-2001. Neuroepidemiology, 29, 78-82. 
https://doi.org/10.1159/000109500

[6] Connor, M.D., Walker, R., Modi, G. and Warlow, C.P. (2007) Burden of Stroke in Black Populations in Sub-Saharan Africa. The Lancet Neurology, 6, 269-278. https://doi.org/10.1016/S1474-4422(07)70002-9

[7] Mapoure, N.Y., Nguenkam, C.B.T., Mbatchou, H.B., Dzudie, A., Coulibaly, A., Mounjouopou, N.G., Vaissaba, E., Luma, N.H., Mouelle, S.A. and Njamnshi, A.K. (2014) Predictors of In-Hospital Mortality for Stroke in Douala, Cameroon. Stroke Research and Treatment, 14, 200-209. https://doi.org/10.1155/2014/681209

[8] Bendriss, L. and Khatouri, A. (2012) Les accidents vasculaires cérébraux ischémiques. Fréquence des étiologies cardiovasculaires documentées par un bilan cardiovasculaire approfondi. À propos de 110 cas. Annales de Cardiologie et d Angéiologie, 61, 252-256. https://doi.org/10.1016/j.ancard.2012.04.011

[9] Dabilgou, A.A., Kyelem, J.A., Dravé, A., et al. (2018) Les accidents vasculaires cérébraux chez le sujet âgé en milieu tropical: aspects épidémiologiques, cliniques et facteurs pronostiques. NPG Neurologie-Psychiatrie-Gériatrie, 18, 133-139. https://doi.org/10.1016/j.npg.2018.01.002

[10] Kuate-Tegueu, C., Mapoure-Njankouo, Y., Gopdjim-Massu, L., et al. (2016) Mortalité par Accident Vasculaire Cérébral et ses Déterminants dans un Hôpital de Référence de Douala (Cameroun). Health Sciences and Diseases, 17, 421-431.

[11] Ossou-Nguiet, P.M., Gombet, T.R., Ampion, M.O., et al. (2014) Genre et accidents vasculaires cérébraux à Brazzaville. Rev Epidemiol Sante Publique, 62, 78-82. https://doi.org/10.1016/j.respe.2013.09.004

[12] Coulibaly, M., Toure, M.K., Traore, A.O., et al. (2019) Les Accidents Vasculaires Cérébraux au CHU "Le Luxembourg" de Bamako: Aspects Cliniques, Thérapeutiques et Pronostiques. Health Sciences and Diseases, 20, 221-229.

[13] Carlsson, G.E., Möller, A., Blomstrand, C., et al. (2003) European Stroke Initiative Recommendations for Stroke Management-Update 2003. Cerebrovascular Diseases, 16, 311-337. https://doi.org/10.1159/000072554

[14] Leys, D., Deplanque, D., Mackowiak-Cordoliani, M.A., Lucas, C., Bordet, R. and Mounier-Vehier, C. (2003) Stroke Prevention: Management of Modifiable Vascular Risk Factors. Journal of Neurology, 250, 1125-1136. https://doi.org/10.1007/s00415-003-0145-x

[15] Niclot, P., Crassard, I., Cohen, A. and Bousser, M.G. (2003) Prévention des Accidents Vasculaires Cérébraux. Encyclopédie Médico-Chirurgicale: Neurologie, 17-046-A-60.

[16] Savsina, M., Dubourgb, D., Coppietersa, Y. and Collarta, P. (2020) Analyse des comorbidités chez les patients hospitalisés pour un accident vasculaire cérébral ischémique et leurs inluences sur la létalité. Annales de Cardiologie et d’ Angéiologie, 69, 31-36. https://doi.org/10.1016/j.ancard.2019.07.008

[17] Karapanayiotides, T., Piechowski-Jozwiak, B. and Van, M.G. (2004) Stroke Patterns, Etiology, and Prognosis in Patients with Diabetes Mellitus. Neurology, 62, 1558-1562. https://doi.org/10.1212/01.WNL.0000123252.55688.05

[18] Corso, G., Bottacchi, E., Giardini, G., Giovanni, M.D., Meloni, T., Campagnoni, M.P. and Morosini, M.V. (2013) Epidemiology of Stroke in Northern Italy: The Cerebrovascular Aosta Registry, 2004-2008. Neurological Sciences, 34, 1071-1081. https://doi.org/10.1007/s10072-012-1185-8

[19] Megherbi, S.E., Milan, C., Minier, D., et al. (2003) Association between Diabetes and Stroke Subtype on Survival and Functional Outcome 3 Months after Stroke: Data from the European BIOMED Stroke Project. Stroke, 34, 688-694. 
https://doi.org/10.1161/01.STR.0000057975.15221.40

[20] Khoury, J.C., Kleindorfer, D., Alwell, K., et al. (2013) Diabetes Mellitus: A Risk Factor for Ischemic Stroke in a Large Biracial Population. Stroke, 44, 1500-1504.

https://doi.org/10.1161/STROKEAHA.113.001318

[21] Shinton, R. and Beevers, G. (1989) Meta-Analysis of Relation between Cigarettes Smoking. British Medical Journal, 298, 789-794. https://doi.org/10.1136/bmj.298.6676.789

[22] Kane, A., Ba, S.A., Sarr, M., et al. (1997) Les embolies cérébrales d'origine cardiaque. Annales de Cardiologie et d’ Angéiologie, 23, 51-57.

[23] Coull, A., Lovett, J.K. and Rothwell, P.M. (2004) Population Based Study of Early Risk of Stroke after Transient. British Medical Journal, 328, Article No. 326. https://doi.org/10.1136/bmj.37991.635266.44

[24] Mohan, K.M., Wolfe, C.D., Rudd, A.G., Heuschmann, P.U., Kolominsky-Rabas, P.L. and Grieve, A.P. (2011) Risk and Cumulative Risk of Stroke Recurrence: A Systematic Review and Meta-Analysis. Stroke, 42, 1489-1494. https://doi.org/10.1161/STROKEAHA.110.602615

[25] Hardie, K., Hankey, G.J., Jamrozik, K., Broadhurst, R.J. and Anderson, C. (2004) TenYear Recurrence and Disability after Stroke in the Perth Community Stroke Study. Stroke, 35, 731-735. https://doi.org/10.1161/01.STR.0000116183.50167.D9

[26] Madureira, S., Guerreiro, M. and Ferro, J.M. (2001) Dementia and Cognitive Impairment Three Months after Stroke. European Journal of Neurology, 8, 621-627. https://doi.org/10.1046/j.1468-1331.2001.00332.x

[27] Henon, H., Durieu, I., Guerouaou, D., Lebert, F., Pasquier, F. and Leys, D. (2001) Poststroke Dementia: Incidence and Relationship to Prestroke Cognitive Decline. Neurology, 57, 1216-1222. https://doi.org/10.1212/WNL.57.7.1216

[28] Pendlebury, S.T. and Rothwell, P.M. (2009) Prevalence, Incidence, and Factors Associated with Pre-Stroke and Post-Stroke Dementia: A Systematic Review and Meta-Analysis. The Lancet Neurology, 8, 1006-1018. https://doi.org/10.1016/S1474-4422(09)70236-4

[29] Arboix, A., Garcia-Erole, L., Massons, J.B., Oliveres, M. and Comes, E. (1997) Predictive Factors of Early Seizures after Acute Cerebrovascular Disease. Stroke, 28, 1590-1594. https://doi.org/10.1161/01.STR.28.8.1590

[30] Burn, J., Dennis, M., Bamford, J., et al. (1997) Epileptic Seizures after a First Stroke: The Oxfordshire Community Stroke Project. British Medical Journal, 315, 1582-1587. https://doi.org/10.1136/bmj.315.7122.1582

[31] Labovitz, D.L., Hauser, W.A. and Sacco, R.L. (2001) Prevalence and Predictors of Early Seizure and Status Epilepticus after First Stroke. Neurology, 57, 200-206. https://doi.org/10.1212/WNL.57.2.200

[32] Lamy, C., Domigo, V., Semah, F., Arquizan, C., Trystram, D., Coste, J. and Mas, J.L. (2003) Early and Late Seizures after Cryptogenic Ischemic Stroke in Young Adults. Neurology, 60, 400-404. https://doi.org/10.1212/WNL.60.3.400

[33] Lossius, M.I., Ronning, O.M., Slapo, G.D., Mowinckel, P. and Gjerstad, L. (2005) Poststroke Epilepsy: Occurrence and Predictors-A Long-Term Prospective Controlled Study (Akershus Stroke Study). Epilepsia, 46, 1246-1251. https://doi.org/10.1111/j.1528-1167.2005.57904.x

[34] Reith, J., Jorgensen, H.S., Nakayama, H., Raaschou, H.O. and Olsen, T.S. (1997) Seizures in Acute Stroke: Predictors and Prognostic Significance: The Copenhagen Stroke Study. Stroke, 28, 1585-1589. https://doi.org/10.1161/01.STR.28.8.1585 
[35] So, E.L., Annegers, J.F., Hauser, W.A., O'Brien, P.C. and Whisnant, J.P. (1996) Population-Based Study of Seizure Disorders after Cerebral Infarction. Neurology, 46, 350-355. https://doi.org/10.1212/WNL.46.2.350

[36] Adoukonou, T., Accrombessi, D., Agbétou, M., et al. (2019) Incidence de l'epilepsie après un accident vasculaire cerebral à Parakou en 2014. The Pan African Medical Journal, 32, Article No. 69.

[37] Arntz, R., Rutten-Jacobs, L., Maaijwee, N., Schoonderwaldt, H., Dorresteijn, L., van Dijk, E. and de Leeuw, F.-E. (2013) Post-Stroke Epilepsy in Young Adults: A Long-Term Follow-Up. PloS ONE, 8, e55498. https://doi.org/10.1371/journal.pone.0055498

[38] Ducrocq, X., Lacour, J.C., Debouverie, M., et al. (1999) Accidents vasculaires cérébraux ischémiques du sujet jeune. Étude prospective de 296 patients âgés de 16 à 45 ans. Revue Neurologique, 155, 575-582.

[39] Kang, K., Park, T.H., Kim, N., et al. (2016) Recurrent Stroke, Myocardial Infarction, and Major Vascular Events during the First Year after Acute Ischemic Stroke: The Multicenter Prospective Observational Study about Recurrence and Its Determinants after Acute Ischemic Stroke I. Journal of Stroke and Cerebrovascular Diseases, 25, 656-664. https://doi.org/10.1016/j.jstrokecerebrovasdis.2015.11.036

[40] Mudzi, W., Stewart, A. and Musenge, E. (2012) Case Fatality of Patients with Stroke over a 12-Month Period Post Stroke. South African Medical Journal, 102, 765-767. https://doi.org/10.7196/SAMJ.5742

[41] Bezzaoucha, A., Bouamra, A., Zeddam, F., et al. (2020) L'accident vasculaire cérébral dans la région de Blida (Algérie) en 2018: Incidence et mortalité d'après un registre de population. La Tunisie Medicale, 98, 8-16.

[42] Kielbergerová, L., Mayer, O., Vaněk, J., Bruthans, J., Wohlfahrt, P. and Cífková, R. (2015) Quality of Life Predictors in Chronic Stable Post-Stroke Patients and Prognostic Value of SF-36 Score as a Mortality Surrogate. Translational Stroke Research, 6, 375 383. https://doi.org/10.1007/s12975-015-0418-6 